\title{
Student operator-assistant pairs: an update
}

\section{A. J. E. Qualtrough, '}

\begin{abstract}
Objective To seek the opinions of undergraduates using the operator-assistant pairs system.
\end{abstract}

Design A five-year evaluation of third-, fourth- and fifth-year students using a short, anonymous questionnaire

Outcome measures This study set out to evaluate, but does not attempt to formally assess, the system.

Result Most students enjoyed working in pairs, citing mutual support and collaborative learning as being the main advantages. However, $67 \%$ of responding third- year students, $79 \%$ of fourth-year students and $54 \%$ of fifth-year students indicated that they did not know why paired working had been introduced.

Conclusions The majority of students found the pairs system advantageous over teacherled situations. It encouraged greater efficiency, mutual support and help and collaborative learning.

$\mathrm{W}$ ithin recent years, the education of dental students has undergone several modifications, some of which have had relatively little impact, while others have had a fundamental effect on course content and the overall approach towards delivery of information and dissemination of skills.

Regardless of any educational change, however large or small, it remains that the graduate should be able to make decisions based on qualitative values, to be proficient in diagnosis and to be able to devise and execute treatment competently ${ }^{1}$. The learning objectives for dental students (similar to those cited for medical students) are aimed towards the desirable attributes expected of the qualified physician who should be altruistic, knowledgeable, skilful and dutiful ${ }^{2}$. Both medical and dental students must acquire a wealth of knowledge and also develop the skills required of the practising clinician in a relatively short period of time.

It has long been recognised that practical instruction can help students learn technical procedures. Textbooks and lectures present factual knowledge, but understanding, problem solving and the acquisition of a professional and caring attitude require

\footnotetext{
${ }^{1}$ Operative Dentistry and Endodontology

University of Manchester Dental School

Higher Cambridge Street

Manchester M15 6FH

${ }^{*}$ Correspondence to A.Qualtrough.

REFEREED PAPER

Received 05.06.00; Accepted 14.07.00

(C) British Dental Journal 2001; 190: 614-618
}

interaction with more experienced individuals $^{3}$. Traditionally, in the clinical situation students have worked either alone or with a dental nurse and productivity has often been used as a measure of assessment. However, there is a different philosophy based on the acceptance that two or more students working together may learn more than each student working individually ${ }^{4}$. Indeed, in the late 1950s, Newcomb demonstrated that peer group influence generally may be a powerful but wasted resource in higher education ${ }^{5}$. There are several advantages to collaborative learning; the main one being that the learning experience is shared rather than information being passively received. Whenever students are actively involved, discover or enhanced $^{6}$. It has also been reported that there are other advantages including efficiency, effectiveness, high order thinking skills are developed and social and team skills are enhanced ${ }^{7}$. Collaborative learning endeavours to ensure that students work together, share responsibility, and are neither competitive nor reliant on each other. As an extension to this concept, recent studies in general education have demonstrated that student-centred methods are superior to teacher-led practices in several respects, including problem-solving, group membership and leadership skills $^{8}$. It has been reported that small groups of medical students learn to diagnose more accurately and with better medical judgement than when working alone ${ }^{9}$. manipulate information, learning is
It has also been found that one of the benefits of discussion groups for medical students was that the process of comparing experiences and ideas strengthened many goals and modified others ${ }^{10}$.

These considerations may be applied to the dental student operator-assistant pair situation in which one student treats the patient and their colleague acts as the assistant. Although the clinical tutor retains an overall supervisory/advisory role, students are encouraged to discuss treatment between themselves and to plan and execute the highest standards of care. Overall responsibility for patient care lies within the team rather than with the individual student. This form of peer group collaboration has the potential to be more stimulating, exacting, productive and effective than the supervisor-led situation. There is also the benefit of enhanced tutor fulfilment.

This approach is not new. In 1975, it was reported that a system of pairing students had been established primarily for the reason that there was an insufficient number of dental nurses, but other factors were thought to be beneficial, including early training of assistant procedures, shorter appointments for patients and a more productive use of space ${ }^{11}$. It was found that there were several additional advantages for the assistant especially, who had to acquire a working familiarity with materials and dental equipment. Students commented that apart from collaborative learning, another benefit was that the assistant could observe the dentist-patient relationship from an objective aspect.

The potential advantages of the dental student operator-assistant pairs are clearly understood. However, other issues such as motivation and 'productivity' may be of concern and have been considered. When efficiency was addressed, it was reported that in a comprehensive patient care system, there was no compromise in the number of completed specific procedures and that there was a significant increase in the number of completed treatment plans ${ }^{12}$. Another area of potential concern is related to the overall quality of care which should, theoretically, be enhanced but, likewise, individual accountability may be sacrificed ${ }^{4}$. 


\section{Background}

The dental student operator-assistant team approach was introduced for both preclinical and clinical undergraduates in the discipline of Restorative Dentistry at the University of Manchester Dental Hospital in October 1993. This change was undertaken following consideration of several issues, including cross-infection control, the limited number of dental nurses and the staff to student ratio which was then considered to be too high. It was common practice at that time, as in many dental schools, for a dental student to act as a single-handed operator and assistant at a stage in their career when chair-side support would be most appropriate. Consequently, patients, many of whom were elderly and/or presenting with complex medical histories, could be left unaccompanied for significant lengths of time while the student waited for a tutor, collected materials, etc. At a time when planning for classroom and clinic refurbishments were also under way, a re-appraisal of teaching methods, with a greater emphasis on the contribution of the whole dental team to patient care, was considered to be timely ${ }^{13}$. It was recognised that there could be potential disadvantages, including students who may 'disappear' from the clinical situation, a possible compromise between clinical experience and practical observations or a fall in student standards and requirements. It was accepted that once established, the change would be irreversible so that unreserved support from staff and students alike was essential. It would also be necessary to monitor and modify any effects of the change, especially during the early days. An initial survey of all dental schools had revealed that there was a wide variation in approach and attitude towards student pairing hence the difficulty of establishing a directly comparative study. Other considerations included differences in requirements and clinical time allocation between schools.

\section{The early days}

Clinic and classroom refurbishments were carefully planned to accommodate fourhanded dentistry in spacious, state-of-the- art units. Issues regarding the time-tables, pair selection and unit allocations were considered at length. The potential problems of the absent partner were addressed by allocation of an unsatisfactory grade for professional attitude to the absentee and this measure proved to be effective. Students were advised that two patients per session must always be booked, unless prior approval had been given, with an operatorassistant role reversal half-way through the session. The operator would be expected to assume overall responsibility for their own patient. In this way, motivation for efficiency and expediency was devolved to the student pair who were also well aware that the minimum number of clinical requirements remained.

Students first worked in pairs when treating children and this method of working was subsequently introduced into the Unit of Operative Dentistry and Endodontology, Prosthodontics and then Periodontics. This approach is now used throughout the school (Figure 1).

Initial findings ${ }^{1}$ indicated that there was a tendency for students to forget the rationale underlying the introduction of paired working, although those who had been recently informed could readily suggest a number of advantages, thus reinforcing the need to regularly re-emphasise the reasoning behind the team approach. A small number of students reported that the pairs were incompatible. In such situations, students are advised to first rationalise the problem themselves, if possible, that working relationships are not always ideal, but any incompatibility must be dealt with professionally and must never compromise patient care. In only a small number of situations have the pairs had to be changed. This does, of course, have a knock-on effect within the rest of the group. To a large extent, this difficulty has been avoided by offering students the opportunity to suggest incompatibilities before pairing is established. Pairs are also changed in the final year.

Evaluation of the longer-term effects of this change in working practice is not easy to assess in a quantitative way. However, it would be reasonable to argue that other, less well-defined criteria are recognised as being of equal, if not greater, relevance to the education of undergraduate dental students than are the more traditional yardsticks. For example, professional attitude, a philosophical approach and a high standard of treatment are essential, yet are difficult to measure. Despite the lack of recognised criteria, it was considered to be essential to establish a system in which any changes in teaching practice could be monitored and provide a mechanism for feedback to the students.

\section{Aim of the study}

The aim of this study was to carry out a fiveyear evaluation of the student operator-assistant pairs system in the Unit of Operative Dentistry and Endodontology at the University of Manchester Dental Hospital.

\section{Methods}

Five years after the introduction of dental student operator-assistant pairs, the opinions of third-, fourth- and fifth-year students were sought by means of a short questionnaire. These questionnaires were distributed at the end of a lecture to each year of clinical students and collected immediately following completion. Students were advised that all responses would be treated confidentially and students could not be identified. Although several questions were open and were

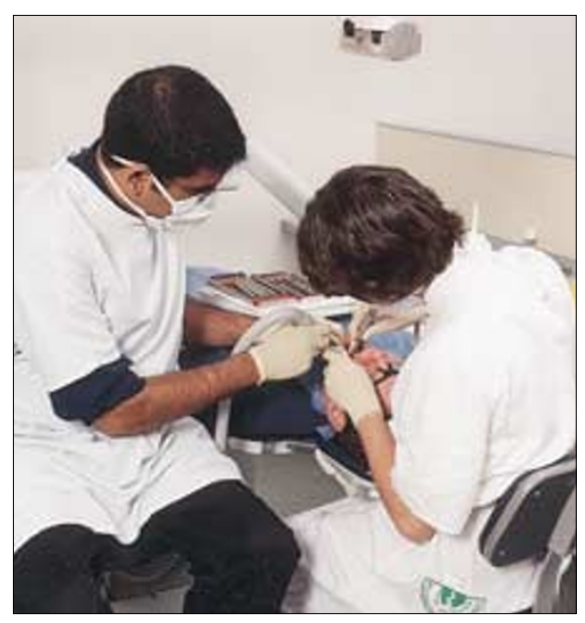

Fig. I Operator-assistant pair in action on the clinic. 
I. a) Do you know why paired working was introduced?

\section{Yes}

No

b) Why?

2. Do you enjoy working with a fellow student?

Yes

No

a) If no, why not?

b) If yes, why?

3. Did you find working in pairs to be of benefit in the Clinical Skills Classroom? Yes

No

a) If yes, why?

b) If not, why?

4. Do you find working in pairs to be of benefit on the clinic?

Yes

No

a) If yes, why?

b) If not, why not?

5. Who do you consider benefits most from student pairing?
a) Staff
b) Students
c) Nurses
d) Patients

6. What are the advantages to?
a) Staff
b) Students
c) Dental nurses
d) Patients

7. What are the disadvantages to?
a) Staff
b) Students
c) Dental nurses
d) Patients

8. Do you consider student pairing to be more or less beneficial than you first anticipated? a) Why more?

b) Why less?

9. What are your responses to the following questions?
a) We get on well as a team
b) We are a good team
c) I feel inhibited by my partner
d) My partner criticises my work
e) My partner is constructive in their comments
f) I would get on better if I worked on my own

$\begin{array}{ll}\text { Yes } & \text { No } \\ \text { Yes } & \text { No } \\ \text { Yes } & \text { No } \\ \text { Yes } & \text { No } \\ \text { Yes } & \text { No } \\ \text { Yes } & \text { No }\end{array}$

10. (For fifth year students only)

Did you consider that working with a nurse was different from working with a colleague? Yes No

If so, what were the main differences?

II. General comment

Fig. 2 Student pairs questionnaire. specifically designed in this way to stimulate the generation of qualitative information, it was possible to categorise most responses into groups.

\section{Results}

The questionnaire is detailed in Figure 2. Data were recorded and tabulated and the main findings are reported below. As the replies were anonymous, absent students could not be identified, hence the return rate was less than $100 \%$. In several cases, students made selective responses leaving some, or several questions unanswered.

Sixty-seven per cent of responding thirdyear students, $79 \%$ of fourth-year students and $54 \%$ of fifth-year students indicated that they did not know why paired working had been introduced. Of those who made suggestions, an insufficient number of dental nurses and financial considerations were proposed as the main factors. Most students ( $83 \%$ of third-years, $81 \%$ of fourth-years and $85 \%$ of fifth-years) indicated that they enjoyed and benefitted from working with a fellow student, although some mentioned that there were partner problems. In general, however, there was positive support with mutual help and support and collaborative learning cited as being the main advantages. Students in the first clinical year seemed to find paired working as being of particular advantage in the clinical situation, less so in the clinical skills classroom when there was a feeling that the other challenges and priorities were of greater importance at this time, especially familiarisation with the fundamental principles and techniques. Students and nurses were considered to be the main beneficiaries of paired working by all three years. Twelve per cent of fifth-year students considered that their patients also benefitted from treatment of higher quality, but on the whole, felt that there were no significant advantages overall. Twenty-three per cent of fifth-years cited time factors and the potential for less than optimal productivity as being their main concerns whereas this was less of a concern to the third-years ( $6 \%$ of respondees).

Eighty-seven per cent of final-year students indicated that they had noticed the difference between working with a dental 


$\begin{array}{lcccc} & & \text { 3rd Year } & \text { 4th Year } & \text { 5th Year } \\ \text { a) We get on well as a team } & \text { Yes } & 78 & 47 & 61 \\ \text { b) We are a good team } & \text { No } & 0 & 5 & 9 \\ & \text { Yes } & 72 & 34 & 54 \\ \text { c) I feel inhibited by my partner } & \text { No } & 7 & 16 & 18 \\ & \text { Yes } & 10 & 9 & 19 \\ \text { d) My partner criticises my work } & \text { No } & 66 & 43 & 53 \\ & \text { Yes } & 21 & 16 & 22 \\ \text { e) My partner is constructive in their comments } & \text { No } & 57 & 36 & 48 \\ & \text { Yes } & 66 & 9 & 54 \\ \text { f) I would get on better if I worked on my own } & \text { No } & 12 & 36 & 17 \\ & \text { Yes } & 9 & 19 & 19 \\ & \text { No } & 69 & 28 & 52\end{array}$

nurse and a student and 63\% cited the efficiency of a trained assistant as being of significant advantage. With respect to general comments, there was an overall consensus that more training in four-handed techniques would be appreciated and that trained nurses should be available. Several students indicated that they would like to be able to select their partner.

\section{Discussion}

This paper is a Delphi type evaluation of the experience of undergraduate students with an operator-assistant pairs system in restorative dentistry. It is not being presented as an evaluation of the efficiency of this system, and, whilst the advantages are recorded in the medical and dental educational literature, there is no attempt at formal outcome assessment in this study.

Most questions stimulated predictable replies. Perhaps the most surprising (and reassuring) responses were those elicited by the statements given in Table 1. It was reassuring to find that despite the fact that students do not select their partner, most appear to get on well and execute their work in a professional, and supportive manner.
An area of concern was that a significant proportion of students demonstrated that they did not know why paired working had been introduced. In addition, the operatorassistant team approach was perceived to hold fewer advantages for third-year students in the clinical skills classroom. These issues have been addressed by re-emphasis of the advantages of the student operatorassistant paired approach to working at frequent intervals. Third-year students are now introduced to the four-handed approach, but are not expected to work in pairs for all procedures in the clinical skills classroom. More importantly, it is recognised that the system must be continually monitored and modified within its own constraints, if appropriate. Feedback in the form of student and staff opinions is always valuable and other mechanisms, such as student assessments, examination performance and external examiners' reports may be used to continue the refinement and evolution of this as a clinical and educational methodology. Another concern facing both staff and students was the issue related to quality of care and 'productivity'. True comparisons between pre- and post-pairing cannot be made at this stage as methods of assessment of student performance have moved away from the recording of individual units towards the philosophy of provision of high quality, total patient care. Nevertheless, the total number of plastic and indirect restorations and root treatments completed by students at the stage of sitting the first part of the final examination has not been significantly affected.

This observation probably reflects the successful working of a system in which paired students work as efficiently, achieve a higher standard, are exposed to a greater number of patients compared with single operator practice and have the added benefit of peer group stimulation. Other aspects of its development may lead to further consideration of peer group education and peer assessment systems in clinical dentistry.

Perhaps one of the greatest advantages is that, for student pairs in a clinical situation, the tutor is always at hand. Total studentdirected learning may be disadvantaged by the absence of a tutor. An example may be cited in medical education in which a study of student-led versus tutor-led problembased learning was carried out. The results 
indicated that outcomes were not affected; indeed the students sometimes took short cuts. However, aspects of the educational, interactive process were, without doubt, lacking ${ }^{14}$

\section{Conclusions}

In conclusion, tutor-led and supervised operator-assistant pairs can be regarded as a clinically tried and tested method of conferring clinical skills in undergraduate dentistry where circumstances allow or favour student pairing. Areas of good practice were considered to be that most students enjoyed working in pairs, citing mutual help and support and collaborative learning as being the main advantages. In addition, they also considered that staff, nurses and patients benefitted from this method of working practice. It is of relevance to consider two contrasting thoughts. In Thomas Woolfe's Look Homeward Angel, Eugene Gant records how, in grammar school he learned to write from his colleague, learning from a peer 'what all instruction failed' to teach him ${ }^{15}$. On the other hand, working together well (in any situation) does not necessarily come naturally, it is something we must learn to do, but is the mechanism in which an approach to life-long learning and optimal patient care is fostered and this must be a fundamental consideration in the education of dental students.

1. Qualtrough, A J E. Student operator assistant pairs. J Dent Edu 1996; 60: 527-532.

2. Learning objectives for medical student education-guidelines for medical schools. Report 1 of the Medical School Objectives Project. Academic Medicine 1999; 74: 13-18.

3. Hunt R C, Massler M. The dental student as teacher. J Dent Edu 1971; 35: 673-676.

4. Bruffee K A. Sharing our toys: Co-operative learning versus collaborative learning. Change 1995; 27: 12-18

5. Bruffee K A. The art of collaborative learning: Making the most of knowledgeable peers. Change 1994; 26: 39-44.
6. Rubin L, Hebert C. Model for active learning. College Teaching 1998; 46: 26-30.

7. Matthews R S, Cooper J L, Davidson N, Hawkes P. Building bridges between cooperative and collaborative learning. Change 1995; 27: 34-40.

8. Bloom B S. Thought processes in lectures and discussions. J Gen Ed 1653; 7: 160-169.

9. Abercrombie M L J. Anatomy of judgement. London: Harmondsworth Press. Penguin, 1964.

10. Rippe J. Bennet, N, Taylor H, Warner C K. Learning from each other: Reflections on a medical student discussion group. J Med Edu 1978; 53: 686-68.

11. Hodgson J M, Avery K T, Shapiro S. Dental students paired for DAU training. J Public Health Dent 1975; 35: 213-214.

12. Evangelidis-Sakellson V. Student productivity under requirement and comprehensive care systems. J Dent Edu 1999; 63: 407-413.

13. Qualtrough A J E. Prepare to pair. Br Dent J 1994; 177: 194-196.

14. Dolmans D. Students as teachers. Medical Education 2000; 34: 11-12.

15. Bruffee K A. Collaboration and the "Conversion of mankind". College English 1984; 46: 635-652. 